\title{
Technical Communication Across the ME Curriculum at Rose-Hulman
}

\section{Dr. Rebecca Bercich, Rose-Hulman Institute of Technology}

Rebecca Bercich is Assistant Professor of Mechanical Engineering at Rose-Hulman Institute of Technology. She received her BS, MS, and $\mathrm{PhD}$ degrees in biomedical engineering from Purdue University in 2016. Her doctoral research focused on the development of wirelessly powered implantable devices to record and stimulate bioelectric activity. She currently teaches in in the areas of mechatronics, measurements, and engineering design. Address: Department of Mechanical Engineering, Rose-Hulman Institute of Technology, 5500 Wabash Ave., Terre Haute, IN 47803 Phone: (812) 877-8121 E-mail: bercich @ rosehulman.edu.

\section{Dr. Sarah Summers, Rose-Hulman Institute of Technology}

Sarah Summers earned her PhD in Rhetoric and Composition at Pennsylvania State University and joined the Rose-Hulman faculty in 2014. Her most recent scholarly work focuses on using design thinking to teach writing. She teaches advanced writing courses including technical writing, grant writing, and digital writing as well as courses in disability studies and visual rhetoric.

\section{Dr. Phillip Cornwell, Rose-Hulman Institute of Technology}

Phillip Cornwell is a Professor of Mechanical Engineering at Rose-Hulman Institute of Technology. He received his Ph.D. from Princeton University in 1989 and his present interests include structural dynamics, structural health monitoring, and undergraduate engineering education. Dr. Cornwell has received an SAE Ralph R. Teetor Educational Award in 1992, and the Dean's Outstanding Teacher award at Rose-Hulman in 2000 and the Rose-Hulman Board of Trustee's Outstanding Scholar Award in 2001. He was one of the developers of the Rose-Hulman Sophomore Engineering Curriculum, the Dynamics Concept Inventory, and he is a co-author of Vector Mechanics for Engineers: Dynamics, by Beer, Johnston, Cornwell, and Self.

\section{James Mayhew, Rose-Hulman Institute of Technology}

James Mayhew is a professor of Mechanical Engineering at Rose-Hulman Institute of Technology. He teaches courses in fluid mechanics, thermodynamics, measurement systems, and aerospace engineering. He was a USAF officer for 13 years before joining Rose-Hulman. 


\title{
Technical Communication across the Mechanical Engineering Curriculum at Rose-Hulman
}

\begin{abstract}
Engineering students can benefit from intentional development and reinforcement of technical communication (TC) skills throughout their undergraduate studies. In this paper we will present a flow chart that captures all TC instruction currently taking place in the mechanical engineering (ME) undergraduate curriculum at Rose-Hulman. This flow chart reveals information and patterns that have existed for years but have never been assembled in an easy-to-access format. We document the process of collecting this information and gathering feedback from colleagues. We then consider how the flowchart might help the department improve the way we teach TC. Using memos as a test case, we develop threshold concepts that could help faculty more intentionally scaffold writing experiences across the curriculum. We conclude by outlining next steps for implementation.

\section{Introduction}

The "Big Picture Committee" of the Mechanical Engineering (ME) Department at Rose-Hulman Institute of Technology has for several years sought to identify common threads of instruction in our curriculum in order to build strategically on students' experiences and knowledge from past courses. The goal of this committee is to improve the quality of student learning by considering not only course content, but also by considering the quantity and timing of various types of skill building. Technical communication (TC) is one of these common threads. We believe the sequence of instruction related to various forms of technical communication (written, oral, and drawing skills) should intentionally develop students' abilities so that by graduation they are prepared for a professional engineering environment.
\end{abstract}

Several research studies have identified the gap between engineering students' writing experiences and the expectations of professional writing in the engineering workplace [1], [2], 
[3], [4]. For example, an analysis contrasting memos produced by civil engineering students and those produced by professional civil engineers found that student writing was less straightforward - both in content and structure - than the writing in professional memos [1]. Student memos failed to meet professional expectations because they resulted in "inaccurate and imprecise content, slower reading for the audience, [and] loss of credibility" [1, p. 209].

Bridging the gap between engineering students' writing instruction and professional expectations has real consequences for the success of novice engineers, especially because learning to write like an engineer is one way that students develop a disciplinary identity [3], [5].

These research studies suggest at least two implications for the way engineering students learn to write. First, writing instruction must be interdisciplinary, that is, it must involve engineering faculty as well as writing specialists. Engineering faculty, particularly those with recent industry experience, have the genre knowledge and subject-matter expertise to recognize professionallyappropriate writing [6], [7]. Writing specialists bring knowledge of how students learn to write, which can influence course elements such as assignment design and feedback practices. Second, writing instruction must be portable. Students must be able to recognize similarities between their writing instruction and workplace writing in order to transfer their communication skills to new contexts [8]. Our work addresses the need for these two elements in our students' writing experience by considering writing instruction within the ME curriculum as well as in general education writing courses. We address portability first by mapping writing and other forms of TC across the curriculum and then identifying ways to intentionally scaffold TC experiences so that students must transfer knowledge from one course to another.

As we considered how to scaffold students' TC experiences, we recognized the need to define the milestones or threshold concepts that students must master in order to be effective communicators in a professional engineering environment. Threshold concepts represent the knowledge necessary to participate in a disciplinary community [9]. Knowledge of a particular threshold concept irreversibly shifts the way a learner thinks about or connects ways of writing, thinking, or practicing in a given field. For example, understanding that the goal of writing is to promote reader understanding is a threshold concept that alters the way students approach the task of writing a memo. The exercise of identifying threshold concepts for communicating in mechanical engineering and then communicating those concepts to both departmental faculty 
and writing faculty "offers a particularly powerful way to begin documenting what student learning looks like and to develop a shared, cross-disciplinary vocabulary that might support meaningful student writing development over time" [10, p. 96]. In other words, threshold concepts support the goals of interdisciplinarity and portability by giving instructors and students a common language for identifying and building communication skills.

In the sections that follow, we first describe the process we used to map TC across the curriculum, including soliciting feedback from faculty about how well the flowchart reflects the practices and goals of the department. Then, using memos as a test case, we suggest threshold concepts that could be used to scaffold memo writing across the curriculum. This test case demonstrates the potential applications of the flowchart and threshold concepts to the interdisciplinary teaching of TC. Finally, we outline the next steps for implementation with the goal of developing a technical communication guide for students and faculty members with

sufficient flexibility to accommodate the different preferences of our colleagues. This guide will be a technical communication compendium that includes threshold concepts, learning outcomes, and practical guidelines for various forms of TC.

\section{Mapping technical communication in the ME curriculum}

In order to begin this project, we first identified what forms of TC are currently required in the ME undergraduate curriculum and in what courses these TC experiences occur. A committee comprised of four faculty - three from ME and one from the Humanities and Social Sciences (HSS) Department - investigated the current state of TC practice and learning by conducting interviews with the faculty members who instruct required ME and HSS courses. At least one faculty instructor for each required ME and HSS course was interviewed. These interviews were performed via brief (5 to 10-minute) face-to-face meetings or email correspondence.

Interviewees were asked what types of TC assignments were used in their course, if those assignments (to the best of their knowledge) were consistent among different instructors for the same course, what guidelines were given for each TC assignment, and whether or not they felt a TC guide would be a useful resource for the ME department.

Based on the information gathered from these interviews, we broadly categorized the types of TC assignments that students complete during their core studies. The categories are: 
1) informal and formal reports

2) memos

3) oral presentations

4) technical drawings

5) other

The "other" category is a catch-all for uncommon or less significant forms of TC such as brief presentations, memos written from a template, lab books, and brochures. These categories allowed us to organize the information collected during the interviews into a single figure based on a plan of study flow chart that has been used in the ME department for many years. Figure 1 shows this flow chart in which each of the TC categories is assigned a color. The colored band(s) contained in a course box indicate which types of TC are required within that course. A half band in a course box indicates that this type of TC is required by some instructors but not others. As we move forward with this project, we hope to eliminate these differences by establishing clear $\mathrm{TC}$ requirements for each course.

We then asked the ME department faculty to look at this TC flow chart and to provide feedback. This took place in an open discussion during an ME department meeting and served to 1) share our progress and results with other faculty stakeholders; 2) gather perceived strengths and weaknesses of our current TC instruction; and 3) help generate proposed modifications to the curriculum.

The faculty observed that there are technical reports required every year, which provides a good framework for incrementally increasing expectations for these reports. However, there is currently no required oral presentation in the sophomore year. Some weaknesses of the flow chart representation that were noted include the absence of the intended audience for each TC assignment and what level of instruction is given for each assignment in each course. The overall response to developing the TC flow chart for the ME curriculum was very positive. One faculty member expressed that it would be very helpful to know where he can either build or depend on previous TC instruction, citing incidents when he was surprised by ME seniors asking what should be included in a formal report. 


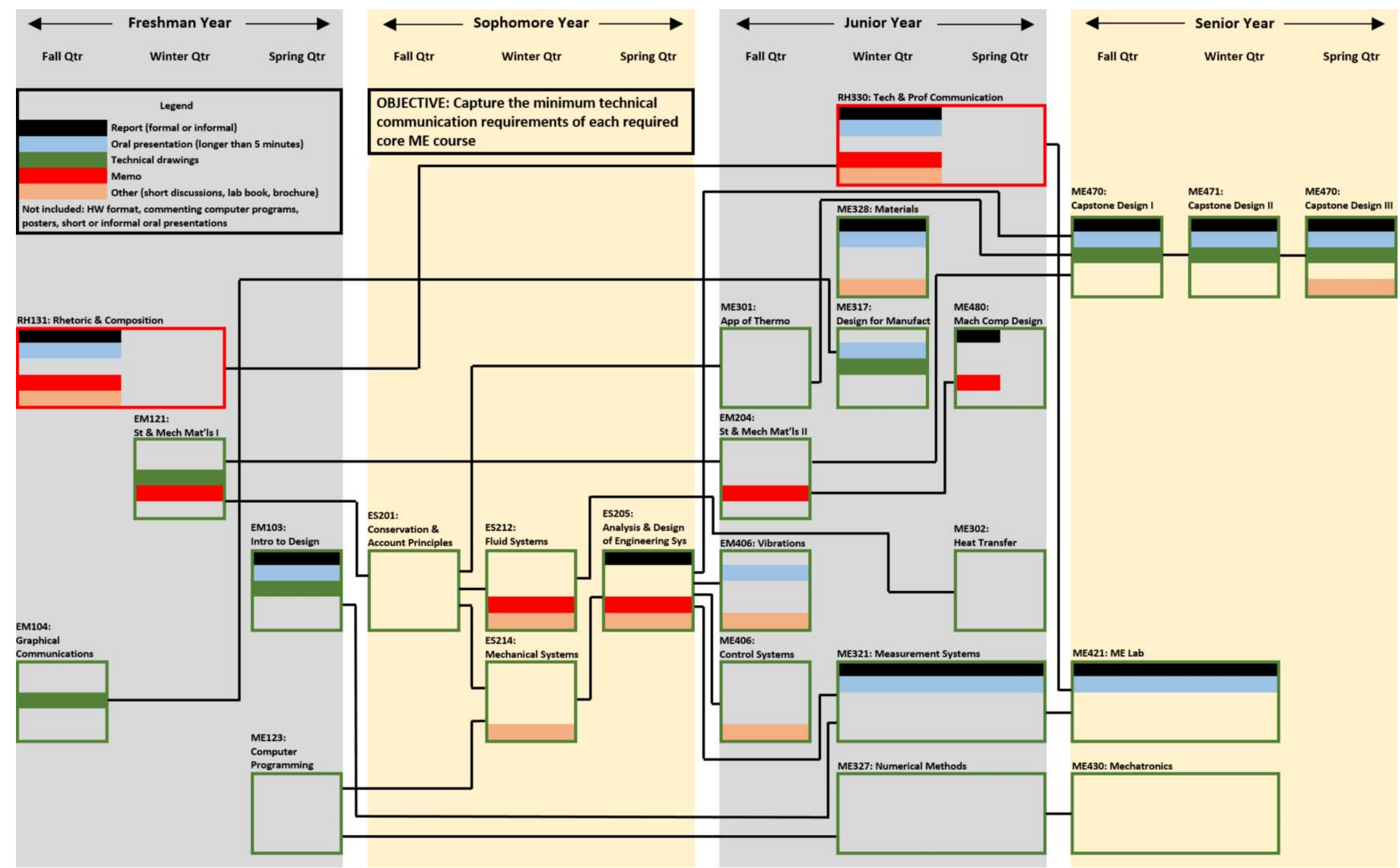

Figure 1. Flow chart of required undergraduate mechanical engineering courses at Rose-Hulman including prerequisite linkages. The minimum technical communication requirements of each course are illustrated with colored bands within each course box. Half colored bands in a course box (such as RH131) indicate that different sections have differing requirements for that type of TC. Course boxes spanning multiple quarters indicate that the course may be completed in either quarter. 


\section{Test case: scaffolding memo writing}

The TC flow chart in Figure 1 effectively illustrates where students practice various forms of TC within the curriculum. The next step is to create a plan for scaffolding each form of TC so that individual assignments reinforce and build upon previous assignments across multiple courses. This plan includes follow-up discussions with faculty instructors who assign each form of TC, identifying threshold concepts based on these discussions, and deciding as a department which courses will help students master each threshold concept. We decided to try this model using memos as a test case.

The effort to scaffold memo writing in the curriculum began by revisiting faculty members who instruct courses with memo assignments. These courses include EM121: Statics and Mechanics of Materials, RH131: Rhetoric \& Composition, ES212: Fluid Systems, ES205: Analysis and Design of Engineering Systems, EM204: Mechanical Systems, RH330: Technical and Professional Communication, and ME480: Machine Component Design. During these visits we asked faculty members to explain the guidelines and expectations for memos that they currently share with students in those courses. These conversations produced the following insights:

1) Students often turn in poor memos, so some instructors provide templates to improve the quality of those memos.

2) Different instructors use memos for different purposes. For example, some use them to justify design decisions while others use them to present data and discuss results.

3) The instruction and feedback provided to students by a writing specialist may emphasize style and mechanics of a written memo, whereas those provided by an ME faculty member might emphasize the accuracy of technical content.

4) There are required structural elements for memos that were consistent for all courses including: 1) the memo should begin with a strong introductory paragraph, 2) all figures and tables need to be referenced in the text before the figure or table appears in the document, 3) all figures should be clearly explained in the text, 4) figure captions go below the figures and table captions go above the tables, and 5) students' observations and assertions concerning results need to be justified. 
Using this feedback, the following proposed threshold concepts for memo writing were developed:

1) Identifying and imitating models is an appropriate and important way to learn the conventions of a genre.

2) The purpose of a memo is to share accurate and complete information concisely.

3) The style and structure of memos should be straightforward to promote reader comprehension.

4) Well-written memos reflect professional identity and influence credibility.

5) Different professional groups have different conventions for memo writing.

It is important that faculty instructors who assign memos not only buy into these threshold concepts, but also coordinate with one another to scaffold learning experiences throughout the curriculum that will support the mastery of these threshold concepts. For example, students may be given a template memo in their first year in EM121 to practice concept 1. In RH330, students may be asked to analyze an ethics case study and respond with a memo that addresses professional values and ethos, practicing concept 4 . The plan to encourage buy-in and coordination among faculty instructors for this effort is described in the next section.

\section{Next steps}

The next steps in this project include:

1) Presenting the proposed threshold concepts related to memo writing for departmental approval and possible modification. If approved these threshold concepts will be the first addition to the ME department's TC guide.

2) Present a scaffolding plan for memo writing to the ME department identifying what threshold concepts and related learning outcomes are associated with each course. This information will also be added to the TC guide. 
3) Work with ME faculty members to identify the characteristics of a professional memo that we expect of our graduates. These practical guidelines will be compiled and added to the TC guide.

4) Develop an assessment plan for the TC scaffolding project.

5) Generate TC guide content (threshold concepts, learning outcomes, and practical guidelines) for other types of technical communication (oral presentations, formal reports, and technical drawings).

6) Develop, consolidate, and share the TC guide with faculty members and students.

\section{Conclusions}

In this paper we discussed the process for identifying all the types of TC that are currently occurring in the ME curriculum at Rose-Hulman. This information was presented in a flow chart showing not only the types of communications, but also the courses where each type of TC is required. We also present a model for scaffolding TC assignments within the curriculum and test this model using written memos as an example of how it can be applied.

\section{References}

1. S. Conrad, "A comparison of practitioner and student writing in civil engineering," Journal of Engineering Education, vol. 106, no. 2, pp. 191-217, 2017.

2. J. Craig, N. Lerner, and M. Poe, "Innovation across the curriculum: Three case studies in teaching science and engineering communication," IEEE Transactions on Professional Communication, vol. 51, no. 3, pp. 280-301, 2008.

3. J. Leydens, "Novice and insider perspectives on academic and workplace writing: Toward a continuum of rhetorical awareness," IEEE Transactions on Professional Communication, vol. 51, no. 3, pp. 242-263, 2008.

4. M. Paretti, “Audience awareness: Leveraging problem-based learning to teach workplace communication practices," IEEE Transactions on Professional Communication, vol. 49, no. 2, pp. 189-198, 2006. 
5. M. Poe, N. Lerner, and J. Craig, Learning to communicate in science and engineering: case studies from MIT. Cambridge, Mass: MIT Press, 2010.

6. R. House, A. Watt, and J. Williams, "The Professional Engineering Genres (PEG)

Project," IEEE International Professional Communication Conference, 2003. IPCC 2003.

Proceedings., 2003.

7. M. Paretti and L. Menair, "Introduction to the Special Issue on Communication in Engineering Curricula: Mapping the Landscape," IEEE Transactions on Professional Communication, vol. 51, no. 3, pp. 238-241, 2008.

8. N. Artemeva, "Stories of becoming: A study of novice engineers," in Genre in a Changing World, C. Bazerman, A. Bonini, and D. Figueiredo, Eds. Fort Collins, CO: WAC Clearinghouse, 2009.

9. J. Meyer and R. Land, Overcoming barriers to student understanding: threshold concepts and troublesome knowledge. London: Routledge, 2012.

10. H. Estrem, "Threshold concepts and student learning outcomes," in Naming what we know: threshold concepts of writing studies, L. Adler-Kassner and E. Wardle, Eds. Logan: Utah State University Press, 2015. 